\title{
Profitability in Complex Investments: Errors of IRR and Other Anomalies, Their Solutions
}

\author{
Alfonso Rodríguez \\ Department of Economic, Financial and Actuarial Mathematics, Barcelona University, Barcelona, Spain \\ Email address: \\ alfonsomrr@telefonica.net.
}

To cite this article:

Alfonso M. Rodríguez. Profitability in Complex Investments: Errors of IRR and Other Anomalies, Their Solutions. International Journal of Economics, Finance and Management Sciences. Vol. 7, No. 3, 2019, pp. 88-94. doi: 10.11648/j.ijefm.20190703.12

Received: February 13, 2019; Accepted: June 3, 2019; Published: August 5, 2019

\begin{abstract}
This investigation conceptually shows, also mathematically and empirically, the unacceptable errors of IRR for the evaluation of the financial profitability in complex investments. The solutions of the IRR are still generally unknown because they are solutions of a polynomial equation without normal mathematical resolution. Through a particular financialvectoral model, this work has managed to solve it, knowing all its possible solutions, which confirm the announced errors. The model also allows us to return to the correct definition of financial profitability, necessarily obviated by the IRR for the lack of a single investment term for all the partial investments existing in the complex investment. Through a Medium Financial Term (MFT), financially equivalent to effective diverse existing investment terms, the work has made possible to return to the strict financial definition of investment profitability through the Profitability Financial Rate (PFR) substitution of the IRR. Through a simulation with five easy complex investments, the work empirically shows the solutions achieved which prove, also empirically, the errors of the IRR. Finally, the work shows other serious anomalies of the IRR in the evaluation of complex investments and in the selection of the optimal investment, derived from its hidden calculus type (the same IRR). Also, it evidences its ignorance on a possible investor degeneration, with serious consequences in the economic meaning of the result.
\end{abstract}

Keywords: Investment, Financing, Investment Mathematics, Financing Mathematics, Financial Profitability, Implicit Interest, IRR, PFR, Investor Degeneration

\section{Introduction}

This work has been possible by the application of a financial-vector model in financial mathematics, very different from the conventional rather oriented to the financial calculation. It has implemented the magnitude "economic time" along with the "monetary magnitude", both basic in the financial phenomenon, the preference for liquidity. This mathematic formalization has allowed to solve serious financial challenges, like the solutions of the financial equation defining IRR (Investment Return Rate). The financial-vector model, introducing the internal operation sum of financial capitals and the financial reduction to simplex of a complex financial operation, has allowed solving such equation achieving all the solutions. Solutions that only are implicit interest in a financial operation but wrongly interpreted as investment productivity by IRR [27].

The financial-vector model has also made possible to apply the strict definition of financial profitability in complex investment, as a relation "amount/term". Through the FAT (Financial Average Term), term financially equivalent to effective investment terms, has solved the absence of a common term in a complex investment necessary, then introducing the PFR (Profitability Financial Rate) as financial instrument substitutive of the IRR.

The financial-vector model differentiates two economic disciplines in Financial Mathematics, the Financing Mathematics and the Investment Mathematics. Imparted the last in Barcelona University (UB) since 1983 as basic discipline. Now, it is convenient exposing here some of its conceptual and formal precisions [29].

\section{Financial Vector-Model}

\subsection{Financial Capital and Equivalence}

This model formalizes a financial capital as a binary vector $(\mathrm{C}, \mathrm{T})$ with magnitudes, monetary $\mathrm{C}$ (amount) and 
temporal $\mathrm{T}$ (deferral-liquidity). In a financial capital set it is defined a financial equivalence through a function $\mathrm{f}(\mathrm{C}, \mathrm{T})$ of their components, called financial factor, parametric respect to a interest rate $(i)$. This equivalence formalizes the financial equilibrium of a credit market. This financial law determinates the preference for liquidity in the economic system, being the financing price interest $(i)$ the parameter that it defines the grade of the preference.

Then, $(\mathrm{C}, \mathrm{T})$ and $\left(\mathrm{C}^{\prime}, \mathrm{T}^{\prime}\right)$ are equivalent capitals conditioned by equation $C^{\prime}=$ C.f $\left(T, T^{\prime}\right)$,

$$
(\mathrm{C}, \mathrm{T}) \sim\left(\mathrm{C}^{\prime}, \mathrm{T}^{\prime}\right) / \mathrm{C}^{\prime}=\mathrm{C} . \mathrm{f}\left(\mathrm{T}, \mathrm{T}^{\prime}\right)
$$

The capital $\left(C^{\prime}, T^{\prime}\right)$ is preferential to capital $(C, T)$ if $C^{\prime}>$ C.f (T,T'),

$$
\left(\mathrm{C}^{\prime}, \mathrm{T}^{\prime}\right)>(\mathrm{C}, \mathrm{T}) / \mathrm{C}^{\prime}>\mathrm{C} . \mathrm{f}\left(\mathrm{T}, \mathrm{T}^{\prime}\right)
$$

\subsection{Financial Sum and Reduction}

The financial sum of a capital set, $\left\{\left(\mathrm{C}_{\mathrm{r}}, \mathrm{T}_{\mathrm{r}}\right)\right\}, \mathrm{r}=1 \ldots \mathrm{n}$, is a capital $(\mathrm{C}, \mathrm{T})$,

$$
(\mathrm{C}, \mathrm{T})=\Sigma\left\{\left(\mathrm{C}_{\mathrm{r}}, \mathrm{T}_{\mathrm{r}}\right)\right\}
$$

where $\mathbf{C}=\Sigma \mathrm{C}_{\mathrm{r}}$ (aggregate input amount) ${ }^{1}$ and $\mathrm{T}$ (average deferral) is conditioned by

$$
\mathrm{C}=\Sigma \mathrm{Cr} . \mathrm{f}(\mathrm{T}, \mathrm{Tr})
$$

Financial set and sum are financially equivalent,

$$
\{(\mathrm{Cr}, \mathrm{Tr})\} \sim(\mathrm{C}, \mathrm{T})
$$

It allows a financial reduction of a capital set to capital sum conserving all the financial properties because the financial equivalence ${ }^{2}$.

For a financial law, with annual parameter (i), the financial average deferral (FAD) is

$$
\begin{aligned}
& \mathrm{T} \equiv \mathrm{T}(\hat{i}) / \mathrm{C}=\Sigma \mathrm{Cr} .(1+\hat{i}) \mathrm{T}(\hat{i})-\mathrm{Tr} \\
& \mathrm{T}(\hat{i})=\frac{1}{\ln (1+i)} \ln \frac{\mathrm{C}}{\Sigma \mathrm{C}_{\mathrm{r}}(1+i)^{-\mathrm{T}_{\mathrm{r}}}}=\frac{1}{\ln (1+i)} \ln \frac{\mathrm{C}}{\mathrm{V}_{0}(i)}
\end{aligned}
$$

For a financial law, with continuous parameter $\rho=\ln (1+$ i), financial average (FAD), is

$$
\mathrm{T}(\rho)=\frac{1}{\rho} \ln \frac{\mathrm{C}}{\Sigma \mathrm{C}_{\mathrm{r}} \cdot \mathrm{e}^{-\rho \cdot \mathrm{T}_{\mathrm{r}}}}=\frac{1}{\rho} \ln \frac{\mathbf{C}}{\mathrm{V}_{0}(\rho)}
$$

1This aggregation is different to the conventional update. Its amount $\mathbf{C}$ respects the accounting aggregation. Also, its $\mathbf{T}$ differs from the updated zero. Updating supposes a monetary-temporal substitution relation different to the capital sum, that it conserves its vectoral definition. Vid. "Ensayo sobre Contabilidad de la Liquidez. Antonio Rodríguez Sastre International Premio, 1979”. A.M. Rodríguez [25]

2E.F. Macaulay defined in 1938 duratio (DUR) as maturity of a bond. as a financial statistical average weighting the coupons with its updated amount, DUR $=\frac{\sum \mathrm{T}_{\mathrm{r}} \cdot \mathrm{C}_{\mathrm{r}}(1+i)^{-\mathrm{T}_{\mathrm{r}}}}{\mathrm{C}_{\mathrm{r}}(1+i)^{-\mathrm{T}_{\mathrm{r}}}}=\frac{\sum \mathrm{T}_{\mathrm{r}} \cdot \mathrm{C}_{\mathrm{r}}(1+i)^{-\mathrm{T}_{\mathrm{r}}}}{\mathrm{V}_{0}(i)}$

Contrary AFD, DUR doesn't respect to the financial equivalence between capitals [24].

\subsection{Simple and Complex Financial Operations}

Financial operations, of financing and investment, are formalized by two capital sets input and output, representing assignments and returns. Simple operations are when its input and output are unitary sets. Another case they are complex operations.

Simple operation: Input $\{(\mathrm{C}, \mathrm{T})\}$, output $\left\{\left(\mathrm{C}^{\prime}, \mathrm{T}^{\prime}\right)\right\}$.

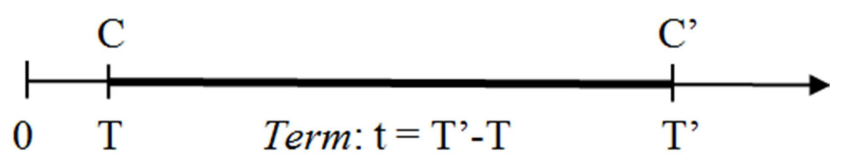

Complex operation:

Input: $\left\{\left(\mathrm{C}_{\mathrm{r}}, \mathrm{T}_{\mathrm{r}}\right)\right\} \equiv\left\{\left(\mathrm{C}_{1}, \mathrm{~T}_{1}\right),\left(\mathrm{C}_{2}, \mathrm{~T}_{2}\right), . .\left(\mathrm{C}_{\mathrm{n}}, \mathrm{T}_{\mathrm{n}}\right)\right\} ; \mathrm{r}=1 . . \mathrm{n}$.

Output: $\left\{\left(\mathrm{C}^{\prime}{ }_{\mathrm{s}}, \mathrm{T}^{\prime}{ }_{\mathrm{s}}\right)\right\} \equiv\left\{\left(\mathrm{C}_{1}, \mathrm{~T}^{\prime}{ }_{1}\right),\left(\mathrm{C}^{\prime}{ }_{2}, \mathrm{~T}^{\prime}{ }_{2}\right), . .\left(\mathrm{C}^{\prime}{ }_{\mathrm{m}}, \mathrm{T}^{\prime}{ }_{\mathrm{m}}\right)\right\} ; \mathrm{s}$ $=1 . . \mathrm{m}$.

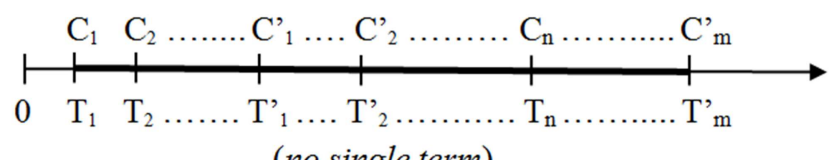

(no single term)

In a complex operation, input amounts $\mathrm{C}_{\mathrm{r}}$ are reintegrated with output amounts $\mathrm{C}_{\mathrm{S}}^{\prime}$ in different terms. Unlike another simple operations, in complex ones there is not an unique term for all their assignations.

\subsection{Financial Reduction to Simple of a Complex Operation}

Reduced input and output of a complex operation to equivalent sums,

$$
\begin{aligned}
& \{(\mathrm{C}, \mathrm{T})\} \sim(\mathbf{C}, \mathbf{T}(i)) \\
& \left\{\left(\mathrm{C}^{\prime}, \mathrm{T}^{\prime}\right)\right\} \sim\left(\mathrm{C}^{\prime}, \mathrm{T}^{\prime}(\mathrm{i})\right)
\end{aligned}
$$

it is possible reducing a financial complex operation to a simple one, because the transitive property of the equivalence relation, being their input and output in reduced operation input and output sums, (C,T(i)) and (C', T'(i)).

Reduced operation,

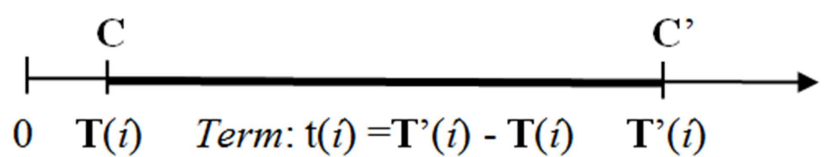

Term of reduced operation $\mathrm{t}(i)$, unlike another simple ones, is not a constant $(\mathrm{t})$, but a function of the interest rate $(i)$. Being $\mathrm{t}(i)$ the difference between the output FAD and the input FAD, of the complex operation, $\mathrm{t}(i)$ it is a financial average term (FAT) for the effective financial terms financially equivalent.

\subsection{Financing and Investment Operations}

Financing and investment operations formally differ by their different financial equilibrium between input and output with respect to the actual market credit. Only financing operations are market operations that respect its equilibrium, 
and the interest as a financing price. Contrary, investment operations pretend obtaining from its financial disequilibrium respect to credit the market a differential result respect to interest, that is the investment yield.

Interest is a price satisfied by a financial service than the foreign capitals provides in an economic activity. Such financial service contributes, as other economic factors, to the creation of value (production), also its particular application (consumption). When it is own financing also it is computable, as opportunity cost. Interest, like any price, is positive always (except a politic monetary intervention). Naturally the interest is contractual with temporal definition.

Investment yield is not a price. It is an economic result of an activity whose input and output are financially unbalanced respect to the credit market. Investment operations don't assume a financial equilibrium, nor are they temporal and contractual operations.

Such serious differences are unavoidable, conceptually and economically But, sometimes they are distorted by an ambiguous use of the economic language. It happens with terms such financing and investment, interest and profitability, return, income result, profitability, etc. It has affected seriously to the definition of investment profitability for IRR, confusing the terms investment with financing and profitability with interest.

\section{Absolute and Relative Investment Yield}

A financial capital that added to investment operation financially equilibrates it formalizes the investment yield, showing its deviation respect to the credit market equilibrium. The amount of this capital is the absolute yield (R), being difference between output amounts and input amounts. The deferral of this capital is the term ( $\mathrm{t}$ ) of the investment operation.

For a simple investment they are, $\mathrm{R}=\mathrm{C}$ '- C (absolute yield) and $\mathrm{t}=\mathrm{T}$ ' - $\mathrm{T}$ (investment term).

For a complex investment it is $\mathrm{R}=\mathrm{C}^{\prime}-\mathrm{C}$ (absolute yield), but there is not a common investment term.

The relative yield (investment profitability) is the ratio of absolute yield (R) with investment amount (C) and investment term $(\mathrm{t})$,

$$
\mathrm{r}=\frac{\mathrm{R}}{\mathrm{C} . \mathrm{t}}
$$

In a complex the amount invested is the input aggregate amount (C), but there is not a common investment term for the inputs, which it prevents the previous financial definition of profitability. Then, the conventional analysis is forced to investigate other alternative definition for it, that IRR interprets confusing complex financing with complex investment and investment profitability with its implicit interest.

\section{Implicit Interest in Complex Financing: Its Solutions}

In a complex financing operation, known their output and input, the interest rate can be deduced as implicit interest, solution of its financial equilibrium equation.

In the origin, they are the current values,

$$
\begin{gathered}
\mathrm{V}_{0}(i)=\mathrm{V}^{\prime}{ }_{0}(i) \\
\Sigma \mathrm{C}_{\mathrm{r}}(1+i)^{-\operatorname{Tr}}=\Sigma \mathrm{C}^{\prime}{ }_{\mathrm{s}}(1+i)^{-\mathrm{T}{ }^{\mathrm{s}}}
\end{gathered}
$$

polynomial equation without possible conventional solution for $(i)$. Therefore, the financial analysis is obligated to calculate an approximate solution following a procedure "test and error" and ignoring another possible solution. The financial-vectoral model has allowed to solve this equation by means of the financial reduction of complex operation to simple one.

\subsection{Solutions of Financial Equilibrium Equation}

Reduced complex financing operation,

$$
\left\{\left(\mathrm{C}_{\mathrm{r}}, \mathrm{T}_{\mathrm{r}}\right)\right\} \sim\left\{\left(\mathrm{C}_{\mathrm{s}}{ }^{\prime}, \mathrm{T}_{\mathrm{s}}{ }^{\prime}\right)\right\} ; \mathrm{r}=1,2 . . \mathrm{n} ; \mathrm{s}=1,2 . . \mathrm{m} .
$$

to simple one,

$$
(\mathrm{C}, \mathrm{T}(\mathrm{i})) \sim\left(\mathrm{C}^{\prime}, \mathrm{T}^{\prime}(i)\right)
$$

must meet the financial equilibrium equation respect to $(i)$

$$
\mathrm{C}(1+i)^{-\mathrm{T}(i)}=\mathrm{C}^{\prime}(1+i)^{-\mathrm{T}^{\prime}(i)}
$$

which, being a polynomial equation lacks of analytical resolution.

Developed as well,

$$
\mathrm{t}(i) \cdot \ln (1+i)=\ln \frac{\mathrm{C}^{\prime}}{\mathrm{C}}=\mathrm{k}
$$

still it lacks of analytical resolution with respect to $(i)$.

Making the variable change, $\rho=\ln (1+i)$,

$$
t(\rho) \cdot \rho=k ; t(\rho)=\frac{k}{\rho}
$$

and unfolding the equation in the system,

$$
\left\{\begin{array}{c}
y=t(\rho) \\
y=\frac{k}{\rho}
\end{array}\right\}
$$

The solutions $(\rho)$ are common solutions of both equations, and their respective intersections of their graphic representations.

Now, it is possible to achieve all possible solutions $(\rho)$, considering

a) $y=t(\rho)$ is a continuous function with the contour conditions:

$$
\begin{aligned}
& \text { - right asymptote, } A=T^{\prime}{ }_{1}-T_{1} \\
& \text { - left asymptote, } B=T^{\prime}{ }_{m}-T_{n}
\end{aligned}
$$


- ordered at origin (avoidable discontinuity), $\beta=$

$$
\frac{\sum \mathrm{C}_{\mathrm{S}}^{\prime} \cdot \mathrm{T}_{\mathrm{S}}^{\prime}}{\mathbf{C}^{\prime}}-\frac{\sum \mathrm{C}_{\mathrm{r}} \cdot \mathrm{T}_{\mathrm{r}}}{\mathbf{C}}
$$

b) $y=k / \rho$ is equation of a equilateral hyperbola, which in quadrants $1^{\circ}$ y $3^{\circ}$ they are,

$\mathrm{k}>0 \Rightarrow \mathbf{C}^{\prime}>\mathbf{C} \Rightarrow \mathrm{R}>$ positive yield), and in quadrants $2^{\circ}$ $\mathrm{y} 4^{\circ}$ they are,

$$
\mathrm{k}<0 \Rightarrow \mathbf{C}^{\prime}<\mathrm{C} \Rightarrow \mathrm{R}<0 \text { (negative yield). }
$$

The parameters $\mathrm{A}, \mathrm{B}, \beta$ and $\mathrm{k}$ allow to anticipate all possible solutions in their number and their sign. They are possible, none solution, single solution or multiple solutions (no more than 3 and one with opposite sign) ${ }^{3}$. Such solutions report respectively in the financing operation, no implicit interest rate and no possible market (Case 1); unique interest rate and unique market (Case 2); multiple types and several markets (no more than three and only possible two positives) (Cases 3, 4 and 5).

Such solutions are coherent for a complex financing operation ${ }^{4}$ but not for a complex investment one, as solutions of the IRR, because the investment profitability does not admit a non-existent evaluation (Case 1), either multiple solutions (Cases 3, 4 and 5). The investment profitability only can admit an unique solution (Case 2) always existent.

\subsection{Empirical Confirmation of IRR Solutions}

Confirming IRR solutions and their financial absurdities, we check them in five simple cases of complex investment. For more contrast, the five cases have same aggregate amounts, $C^{\prime}=210$ and $C=200$. and same absolute yield, $\mathrm{R}=10$. Only they differ by their amounts and their deferrals ${ }^{5}$.

We show their for all the input and output, amounts, absolute yield, predictive solution parameters, graphics of their financial functions FAT and their equilateral hyperbolas, the solution intersections and numerical solutions, with a very brief comment on the results.

Case 1

Input: $\{(100,1),(50,2),(50,3)\} . \mathrm{C}=200$

Output: $\{(100,0),(90,4),(20,5)\}$. $C^{\prime}=210$

$\mathrm{R}=\mathrm{C}^{\prime}-\mathrm{C}=10$

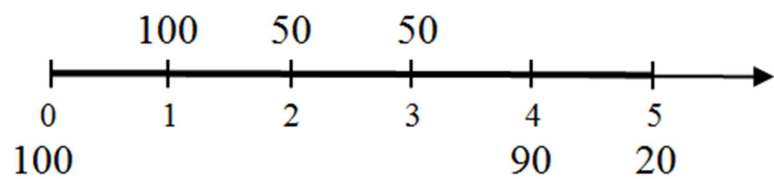

Graphic 1.

3Through a computer application designed for it, we can calculate all solutions of IRR in any complex investment operation, in addition representing them graphically.

4Multiple equilibrium is possible, because particular temporal distributions of deferral financially compensable.

5They show the importance of temporary distributions of amounts for investment profitability.

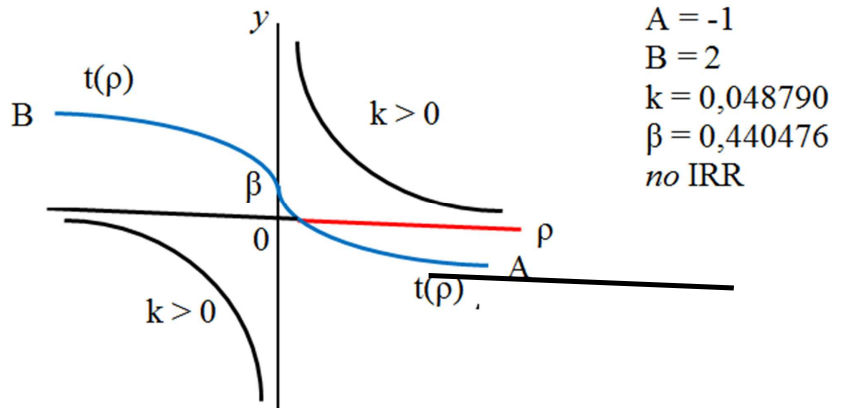

Analysis: An absurd the inexistence of an IRR. Even more if we consider existing positive absolute yield, $\mathrm{R}=10>0$.

Case 2

Input: $\{(90,0),(60,1),(50,2)\} . \mathrm{C}=200$

Output: $\{(100,3),(80,4),(30,5)\} . C^{\prime}=210$

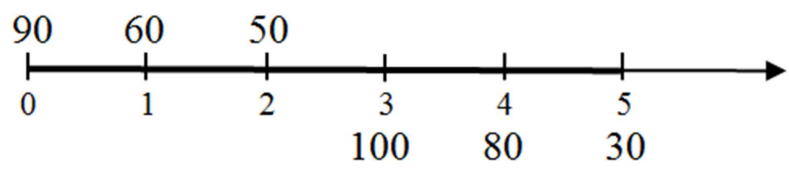

Graphic 2

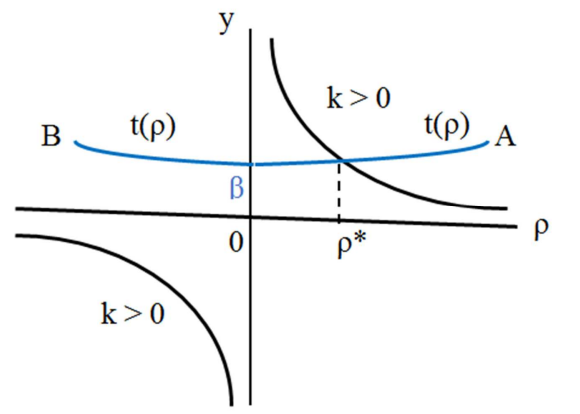

$\mathrm{A}=3$

$\mathrm{B}=3$

$\mathrm{k}=0,048790$

$\beta=2,819048$

one IRR

Analysis: One IRR $>0, \rho^{*}=0,017012 \sim \mathrm{r}^{*}=1,72 \%$ (later analysis)

Case 3

Input: $\{(60,0),(90,2),(50,6)\} \cdot \mathrm{C}=200$

Output: $\{(100,1),(90,4),(20,5)\}$. $C^{\prime}=210$

$\mathrm{R}=\mathrm{C}^{\prime}-\mathrm{C}=10$

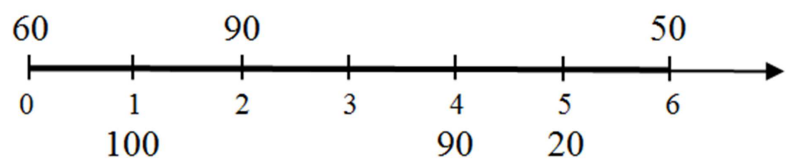

Graphic 3

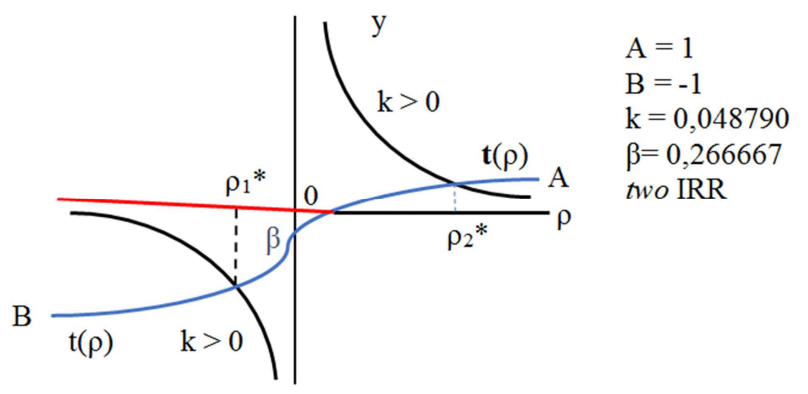

$\operatorname{IRR}<0, \rho_{1} *=-0,104573 \sim \mathrm{r}_{1} *=-9,93 \%$ 
$\operatorname{IRR}>0, \rho_{2} *=0,283870 \sim \mathrm{r}_{2} *=32,83 \%$

An absurd two profitability rates. Even more considering their opposite sign.

Case 4

Input: $\{(100,1),(50,3),(50,4)\} . \mathrm{C}=200$

Output: $\{(100,0),(90,2),(20,5)\} . C^{\prime}=210$

$\mathrm{R}=\mathrm{C}^{\prime}-\mathrm{C}=10$

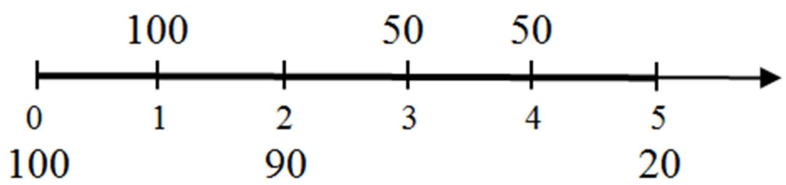

Graphic 4

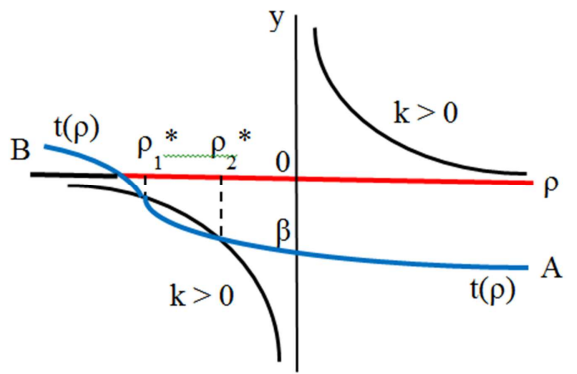

$A=-1$

$\mathrm{B}=1$

$\mathrm{k}=0,048790$

$\beta=-0,916667$

two IRR

Analysis:

IRR $<0, \rho_{1}^{*}=-00,084754 \sim \mathrm{r}_{1}{ }^{*}=-66,20 \%$

IRR $<0, \rho_{2}{ }^{*}=-0,054338 \sim r_{2}{ }^{*}=-5,29 \%$

An absurd two profitability rates. Even more negative both being $\mathrm{R}=10>0$.

Case 5

Input: $\{(100,1),(90,2),(10,5)\} . \mathrm{C}=200$

Output: $\{(80,0),(40,3),(90,4)\}$. C'=210

$\mathrm{R}=\mathrm{C}^{\prime}-\mathrm{C}=10$

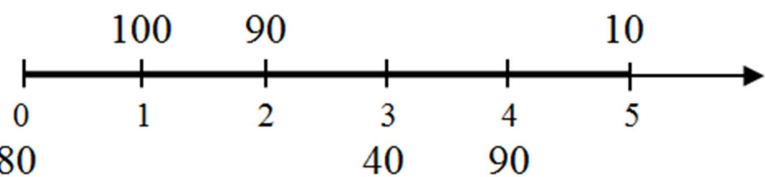

Graphic 5

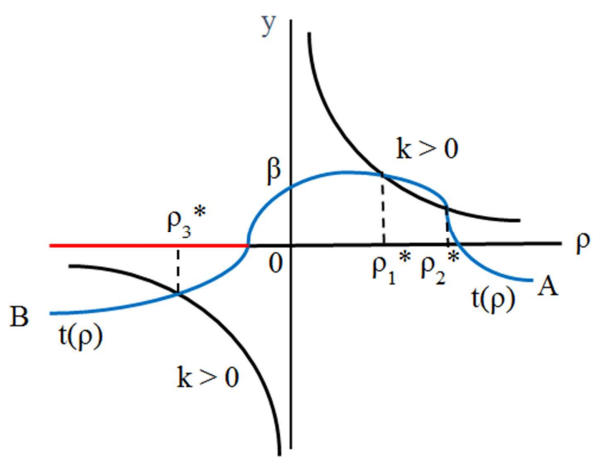

$A=-1$

$\mathrm{B}=-1$

$\mathrm{k}=0,048790$

$\beta=0,635714$

three IRR

Analysis:

IRR $<0, \rho_{1} *=-2,231567 \sim \mathrm{r}_{1} *=-89,26 \%$

IRR $>0, \rho_{2}{ }^{*}=0,095698 \sim \mathrm{r}_{2} *=10,04 \%$

IRR $>0, \rho_{3} *=0,367966 \sim \mathrm{r}_{3} *=44,48 \%$

An absurd three profitability rates. Even more negative one being $\mathrm{R}=10>0$.

\section{Financial Profitability Rate (FPR): Replacing the IRR}

The lack of unique term (t) in a complex investment prevents conventional analysis applying the correct financial definition of profitability. Searching an alternative definition, the IRR incurs in inacceptable errors. Nevertheless, the reduction to simple of a complex financial operation allows to save such difficulty, considering unique term in the complex operation the term of the reduced one, the Financial Average Term (FAT). It allows to return to the correct definition of financial profitability, as an annual rate, as a continuous rate,

$$
\overline{\mathrm{r}}=\frac{\mathrm{R}}{\operatorname{C.t}\left(i^{\circ}\right)} \text { (annual) or } \bar{\rho}=\frac{\mathrm{k}}{\mathrm{t}\left(i^{\circ}\right)} \text { (continuous) }
$$

We call such rate Financial Profitability Rate (FPR) and we postulate it substitute of IRR.

Now, we contrast the FPR results with IRR results in the five cases previously simulated. Let's consider a financial interest law with annual rate $i^{\mathrm{o}}=1.50 \%$, equivalent continuous rate $\rho^{\circ}=\ln \left(1+i^{\circ}\right)=0.014889$.

Case 1:

Input: $\{(100 ; 1),(50 ; 2),(50 ; 3)\} . \mathrm{C}=200$

Output: $\{(100 ; 0),(90 ; 4),(20 ; 5)\}$. C' $=210$

$\mathrm{R}=\mathrm{C}^{\prime}-\mathrm{C}=10$

$\mathrm{t}\left(\rho^{\mathrm{o}}\right)=0,41$ (FAT: 4m. y $28 \mathrm{~d}$.)

$\rho^{*}$ (no IRR)

$\bar{\rho}=0,118327 \sim \overline{\mathrm{r}}=12,56 \%$ (FPR)

Analysis. FPR determines an investment profitability of $12,56 \%$. IRR does not calculate any.

Case 2:

Input: $\{(90 ; 0),(60 ; 1),(50 ; 2)\} . \mathrm{C}=200$

Output: $\{(100 ; 3),(80 ; 4),(30 ; 5)\} . \mathrm{C}^{\prime}=210$

$\mathrm{t}\left(\rho^{\circ}\right)=2,87$ (FAT: 2a. $10 \mathrm{~m}$. y $7 \mathrm{~d}$.)

$\mathrm{R}=\mathrm{C}^{\prime}-\mathrm{C}=10$

$\rho^{*}=0,017012 \sim \mathrm{r}^{*}=1,72 \%$ (unique IRR)

$\bar{\rho}=0,017013 \sim \bar{r}=1,73 \%$ (FPR)

Analysis: FPR and IRR calculate similar investment profitability, $1,73 \%$ and $1,72 \%$. It is because IRR is close to the market interest rate.

Case 3:

Input: $\{(60 ; 0),(90 ; 2),(50 ; 6)\} . \mathrm{C}=200$

Output: $\{(100 ; 1),(90 ; 4),(20 ; 5)\} . C^{\prime}=210$

$\mathrm{R}=\mathrm{C}^{\prime}-\mathrm{C}=10$

$\mathrm{t}\left(\rho^{\mathrm{o}}\right)=0,28$ (FAT: 3m. y 12d.)

$\rho_{1}^{*}=-0,104573 \sim r_{1}^{*}=-9,93 \%$ (IRR)

$\rho_{2} *=0,283870 \sim \mathrm{r}_{2} *=32,83 \%$ (IRR)

$\bar{\rho}=0,174251 \sim \bar{r}=19,14 \%$ (PFR)

Analysis: Two disappear IRR, even more, with different sign. The PFR determinates a different investment profitability, of $19,14 \%$.

Case 4: Input: $\{(100,1),(50,3),(50,4)\} . \mathrm{C}=200$ 
Output: $\{(100,0),(90,2),(20,5)\} . C^{\prime}=210$

$\mathrm{R}=\mathrm{C}^{\prime}-\mathrm{C}=10$

$\mathrm{t}\left(\rho^{\mathrm{o}}\right)=-0,92<0$ (FAT: $-11 \mathrm{~m}$ y $\left.6 \mathrm{~d}\right)$ (degenerate operation)

$\rho_{1}^{*}=-0,084754 \sim \mathrm{r}_{1} *=-66,20 \%$ (IRR)

$\rho_{2} *=-0,543380 \sim \mathrm{r}_{2} *=-5,29 \%$ (IRR)

$\bar{\rho}=-0,052962 \sim \bar{r}=-5,16 \%$ (FPR)

Analysis: Two disappear IRR. The PFR calculates an investment profitability of $5,16 \%$ (the sign is opposite because the operation is degenerate).

Case 5: Input: $\{(100 ; 1),(90 ; 2),(10 ; 5)\} . \mathrm{C}=200$

Output: $\{(80 ; 0),(40 ; 3),(90 ; 4)\} . C^{\prime}=210$

$\mathrm{R}=\mathrm{C}^{\prime}-\mathrm{C}=10$

$\mathrm{t}\left(\rho^{\circ}\right)=0,62$ (FAT: $7 \mathrm{~m}$ y $15 \mathrm{~d}$.)

$\rho_{1}^{*}=-2,231567 \sim \mathrm{r}_{1} *=-89,26 \%$ (IRR)

$\rho_{2} *=0,095698 \sim \mathrm{r}_{2} *=10,04 \%$ (IRR)

$\rho_{3} *=0,367966 \sim \mathrm{r}_{3} *=44,48 \%$ (IRR)

$\bar{\rho}=0,079100 \sim \overline{\mathrm{r}}=8,23 \%$ (PFR)

Analysis: Three disappear IRR one with different sign. The PFR determinates an investment profitability of $8,23 \%$.

\section{6. "Degenerated" Investment Operation}

A complex investment may have a negative FAT, $\mathrm{t}(\mathrm{i})<0$, because the FAT of output is less than the FAT of input. It can happen when an investment operation initially receives lost fund subventions (Case 4). Negative FAT converts cost in performance applying excess liquidity. Such anomalies justify to call "degenerate" to such operations ${ }^{6}$.

A negative term supposes a temporal abnormality that contradicts the natural temporality of an investment but it has a great influence on the investment profitability. Making the fiction existing the opponent "counter-investor" in the system, with input and output opposite, its financial profitability would have opposite economic sense. It would be "zero-sum" with the financial profitability of the natural investor.

Counter investment operation (not degenerate),

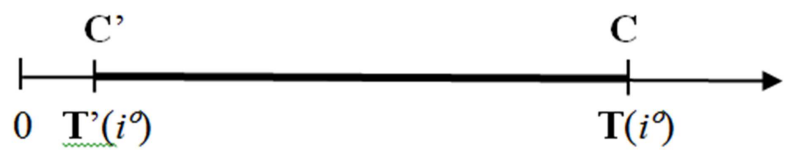

being $[\mathrm{FAT}] \equiv\left[\mathrm{t}\left(i^{\circ}\right)\right]=\mathbf{T}\left(i^{9}\right)-\mathbf{T}^{\prime}\left(i^{\sigma}\right)=-\mathrm{t}\left(i^{9}\right)>0(-\mathrm{FAT})$.

Being other parameters,

$$
\begin{aligned}
& {[\mathrm{R}]=-\mathrm{R} ;[\mathrm{k}]=(-\mathrm{k})} \\
& {[\bar{\rho}]=\frac{[\mathrm{k}]}{\left[\mathrm{t}\left(i^{\circ}\right)\right]}=\frac{-\mathrm{k}}{-\mathrm{t}\left(i^{\circ}\right)}=(\bar{\rho})}
\end{aligned}
$$

and both investment profitability, $[\mathrm{FPR}]=(\mathrm{FPR})$.

Being (FPR) "zero-sum" with [FPR], its economic sense (profit or lost) has opposite sign, thus coinciding sense with (R).

Conventional analysis does not know FAT either its

6In previous graphics we have red highlighting $\rho$ intervals where FAT behaves negative. possible degeneration. Also, it affecting equally to IRR introducing a very serious error for the investment result [27].

\section{Other Serious Anomalies of the IRR}

The IRR does not inform about its calculative type. The calculative type is implicit in the calculation of IRR. It coincides with IRR, being a serious error for all financial analysis ignoring the interest market rate, because it shows the actual degree of preference for the liquidity existing. The IRR hides the calculating type tautologically using for it its own result. Thus, IRR is evaluating the investment profitability in a nonexistent virtual market.

But, further, it is a serious cause of errors for the evaluation and the selection of investment projects in an investor alternative. In fact, calculating IRR with itself type, it applies different calculative types on each investment option (own IRR), so violating the most elemental legitimacy on the financial selection.

Also, when IRR evaluates lost, the calculative type is negative (financial absurd), however it is possible that evaluated the financial profitability with the positive interest of market type, it be very profitable (empirically verified).

\section{Last Considerations and Final Conclusions}

About the abnormal actual permanence of IRR

The demonstrated errors and dysfunctions that the use of the IRR implies, they make incomprehensible their permanence as the usual financial instrument for the evaluation and selection in complex investment. But it has a simple explanation:

a) The conceptual errors are supported in an ambiguous economic language that confuses financing and investment, interest and yield, return, income, result, etc.

b) The absurd IRR solutions are little known. They are published in teaching books as "Mathematics of investment" since 1983, but not in scientific magazines.

c) Other IRR dysfunctions are not verifiable by alternative instruments, nonexistent or not enough defunded (as the PFR). On the other hand, IRR provides approximate solutions when IRR do not very deviate from the market interest type, although it implies short investment profitability.

The mathematical formalization.

The work develops an own financial-vectoral model. It has allowed achieving all the solutions of the financial equilibrium equation of IRR, until now unknown because its polynomial nature. Also, it has allowed defining a financial average term (FAT) that substitutes all effective terms of a complex investment, conserving all their financial proprieties.

The substitution IRR by PFR.

It would not have practical sense disqualifying IRR if it 
were not followed of a substitute instrument. It has been possible to return to the strict definition of investment profitability thus the FAT, enabling the Profitability Financial Rate (PFR) as a financial instrument substitutive of IRR for the evaluation of the investment profitability in complex investment, also for the optimal selection of the investment in an investor alternative.

\section{References}

[1] Adler M. "Global Fixed-Income Portfolio Management". Financial Analyst Journal. September-October 1983.

[2] Alexander, G. J. and Resnick. "Using Linear and Goal Programming to Immunize Bond Port-folios". Journal of Banking and Finance 1985.

[3] Babbel, D. F. "Duration and the Term Structure of Interest Volatility". Edited in Innovations in Bond Portfolio Management by Bierwag, Kaufman and Toevs. 1983.

[4] Babbel, D. F. "Real Immunization with Indexed Bonds". Financial Analysts Journal, November-December 1984.

[5] Babcock, G. C. "Coment: Duration and Bond Portfolio Analysis". Journal of Financial and Quantitative Analysis, November 1978

[6] Babcock, G. C. "Duration as a Weighted Average of two Factors”. Financial Analysists Journal, Mars-April 1985.

[7] Bierwag, G. O. "Immunization, Duration and the Term Structure of Interest Rates". Journal of Financial and Quantitative Analysis, December, 1977.

[8] Bierwag, G. O. "Measures of Duration”. Economic Inquiry, October 1978.

[9] Bierwag, G. O. "Dynamic Immunization Portfolio Policies". Journal of Banking and Finance, April 1979.

[10] Bierwag, G. O. and Kaufman, G. G. "Coping with the Risk of Business: A Note”. Journal of Business, Julee 1977.

[11] Bierwag, G. O. and Kaufman, G. G. "Duration Gap for Financial Institutions". Financial Analysts Journal, MarsApril 1985.

[12] Bierwag, G. O., Kaufman, G. G. and Khang C. "Duration and Bond Portfolio Analysis: An Overview”. Journal of Financial and Quantitative Analysis, November 1978.

[13] Bierwag, G. O., Kaufman, G. G., Schweitzer, R. L. and Toevs, A. "Innovations in Bond Portfolio Management: Duration, and Immunization”. JAI Press Inc. London. 1983.
[14] Bierwag, G. O., Kaufman, G. G., and Toevs, A. "Single Factor Duration Models in a General Equilibrium Framework". The Journal of Finance, May 1982.

[15] Bierwag, G. O., Kaufman, G. G., and Toevs, A. "Duration: Its Development and Use in Bond Portfolio Management". Financial Analysists Journal, Julee-August 1983.

[16] Bierwag, G. O., Kaufman, G. G., and Toevs, A. "Immunization Strategies for Funding Multiple Liabilities". Journal of Financial and Quantitative Analysis, Mars 1983.

[17] Bierwag, G. O., Kaufman, G. G., and Toevs, A. "Recent Development in Bond Portfolio Immunization Strategies". JAI Press 1983.

[18] Bierwag, Kaufman and Toevs. "Innovations in Bond Portfolio Management: Duration Analysis and Immunization". JAI Press Greenwich 1983.

[19] Bierwag, G. O. and Khang, C. "An Immunization Strategy is a Minimax Strategy”. Journal of Finance, May 1979.

[20] Fisher, I. "The theory of interest". New York Macmillan (1930).

[21] Fisher, L. "An algorithm for Finding Exact Rates of Return". The Journal of Business, January 1966.

[22] Fisher, L. and Leibowitz, M. L. "Effects of Alternative Anticipations of Yield-Curve Behavior on the Composition of Immunized Portfolios and their Targets Returns". Innovations Management: Duration Analysis and Immunization. JAI Press. 1983.

[23] Fisher, L. and Weil, R. L. "Coping with the Risk of Interest Rate Fluctuations, Returns to Bondholders from Naïve and Optimal Strategies”. Journal of Business, October 1971.

[24] Macaulay, F. "Duration coupon bono". National bureau of economic research (1938).

[25] Rodríguez A. M. "Ensayo sobre Contabilidad de la Liquidez. Premio Internacional Antonio Rodríguez Sastre, 1979”. Ed. Censores Jurados de Cuentas de España.

[26] Rodríguez, A. M. "Matemática de la Financiación". Autor. UB ed. 1994.

[27] Rodríguez, A. M. "Matemática de la Inversión". Autor. UB ed. 1997.

[28] Rodríguez, A. M. "Inmunidad Financiera". Autor. UB ed. 1994.

[29] Rodríguez, A. M. "Fundamentos de la Matemática Financiera". Autor. UB ed. 1998. 